\title{
Recent advances in materials for extended-release antibiotic delivery system
}

\author{
Ping Gao, Xin Nie, Meijuan Zou, Yijie Shi and Gang Cheng
}

To maintain antimicrobial activity, frequent administration of conventional formulations of many antibiotics with short half-life is necessary. Otherwise, concentration under MIC occurs frequently in the course of anti-infective treatment, which induces antibiotic resistance. By maintaining a constant plasma drug concentration over MIC for a prolonged period, extended-release dosage forms maximize the therapeutic effect of antibiotics while minimizing antibiotic resistance. Another undoubted advantage of extended-release formulation is improved patient compliance. For better release properties, many materials have been introduced into the matrix and coating extended-release system in the past few years. Materials that have been widely used in industry are hydrophilic matrix materials such as hydroxypropylmethylcellulose. The excellent biocompatibility and extensive laboratory studies provide biodegradable polymers great potential for industrial applications. In addition, it seems like the researches on tailored materials that are obtained by chemical modification of the existing materials or combination of different carriers in physical mixtures have a long way to go. Meanwhile, with the development of polymers and inorganic porous nanocarriers, nanotechnology is applied increasingly for the extended delivery of antibiotics. This review highlights the development of materials used in extended-release formulation and nanoparticles for antibiotic delivery. We also provide an overview of the antibiotic extended-release products that have provided clinical benefit or are undergoing the clinical trial. The Journal of Antibiotics (2011) 64, 625-634; doi:10.1038/ja.2011.58; published online 3 August 2011

Keywords: antibiotic resistance; coating material; complex; extended release; matrix material; nanoparticles

\section{INTRODUCTION}

Since Alexander Fleming discovered penicillin in 1928, hundreds of antibacterial drugs have been introduced into clinical use and many infectious diseases have been overcome. However, with their extensive application, one of the most serious problems of current medicineantimicrobial resistance-arises, which limits the therapeutic effect of conventional therapy. Many researchers are making efforts to discover new antibiotics, whereas some other studies are focused on improving the clinical outcomes of currently available antibacterial drugs by using new formulations. Extended-release delivery system is one of the investigations that is being carried out to decrease the induction of antibiotic resistance. The terms 'sustained release', 'prolonged release' and 'slow release' are synonymous with 'extended release'. As antiinfection treatments often involve a long course of therapy, sufficient antibiotic exposure is needed to ensure the eradication of the microorganism. However, many patients tend to interrupt treatment once they feel better, and thus the incomplete treatment may aggravate the development of antibiotic resistance. Besides, many antibiotics have short half-life values and need to be administered frequently, which also contributes to patient incompliance. The poor compliance often leads to treatment failure or increases the cost of health-care resources such as the requirement for additional agents and hospital admission. It is recognized that extended-release preparation is advantageous to improve patient compliance, as frequent administration can be reduced by maintaining a constant plasma drug concentration over a prolonged period of time. ${ }^{1}$ For example, for azithromycin, a long serum half-life $(\sim 68 \mathrm{~h})$ antibiotic, the conventional preparation allows for a short 3 -day $\left(500 \mathrm{mg} \mathrm{day}^{-1}\right.$ for 3 days) or 5 -day $(500 \mathrm{mg}$ on day 1 followed by $250 \mathrm{mg}$ on days 2-5) course of therapy, whereas azithromycin sustained-release microsphere for oral suspension (Zmax) permits a single-dose administration. Clinical applications have demonstrated the undoubted advantages of improved compliance and convenience of the single-dose regimen. ${ }^{1}$

Furthermore, sustained-release formulations can improve the therapeutical index of antibiotics. Antimicrobial agents are commonly divided into two major categories on the basis of their pharmacodynamics: time-dependent and concentration-dependent antibiotics. The time-dependent antibiotics, such as $\beta$-lactams, macrolides (except for azalides), tetracyclines and clindamycin, exert bactericidal effect when drugs are maintained above the MIC. ${ }^{2}$ For these agents, the time that therapeutic drug concentrations are above the MIC (T $>$ MIC) is the primary parameter and should be kept for a minimum standard to achieve the desired clinical outcomes. ${ }^{3}$ In addition, dosage under the threshold may promote the development of antibiotic resistance. ${ }^{4}$ Therefore, continuous infusion has been proposed and its clinical advantage against antibiotic resistance over intermittent bolus for 
time-dependent antimicrobials has been confirmed. ${ }^{5-7}$ Nevertheless, this approach has certain limitations, such as low physicochemical stability and patient inconvenience. For obtaining all the advantages of continuous infusion while avoiding the limitations, sustained-release preparation is a good substitute. For instance, amoxicillin/clavulanic acid extended-release formulation (Augmentin XR) has been demonstrated to extend amoxicillin exposure and killing time for a greater proportion of the dosing interval than that achieved by conventional formulations. Clinical trials have also indicated that the pharmacokinetic-enhanced formulation provided higher treatment success when compared with its immediate-release preparations with lower cost. ${ }^{8}$ Another example is clarithromycin extended-release tablets (Biaxin), the release profile of which is shown in Figure 1. Compared with clarithromycin immediate release, the extended-release preparation remained $\mathrm{T}>\mathrm{MIC}$ for a longer duration and achieved better clinical cure. $^{9}$

Concentration-dependent antibiotics include aminoglycosides, quinolones, azalides (azithromycin), ketolides and vancomycin. Different from the time-dependent antibiotics, these agents achieve increased bacteria killing with increased levels of drugs. In addition, these agents have an associated concentration-dependent postantibiotics effect. The peak concentration $\left(\mathrm{C}_{\max }\right)$ and area under the concentration curve determine the clinical outcomes of these antibiotics. It is demonstrated that higher $\mathrm{C}_{\max } / \mathrm{MIC}$ and area under the concentration curve/MIC correlate with a significantly higher survival rate in preclinical models of infection and help prevent the development of resistance. ${ }^{10}$ Sustained-release formulations can provide controllable drug release to maximize the $\mathrm{C}_{\max }$ and minimize the toxicity. For example, ciprofloxacin extended-release formulation (Cipro XR or Cipro XL), which permits convenient once-daily treatment, provides a more favorable $\mathrm{C}_{\max }$ value and less interpatient variability than the immediate-release twice-daily formulation. ${ }^{11}$

Many sustained-release antibiotic preparations have come into the market and have shown superiority over conventional formulations, as is summarized in Table 1. Obviously, matrix-type extended-release technology occupies the major market share of sustained-release antibiotic products. Besides, a sustained-release formulation of amikacin (Arikace, liposomal amikacin for inhalation) will enter clinical trial phase III in August 2011. ${ }^{12}$ With the development of

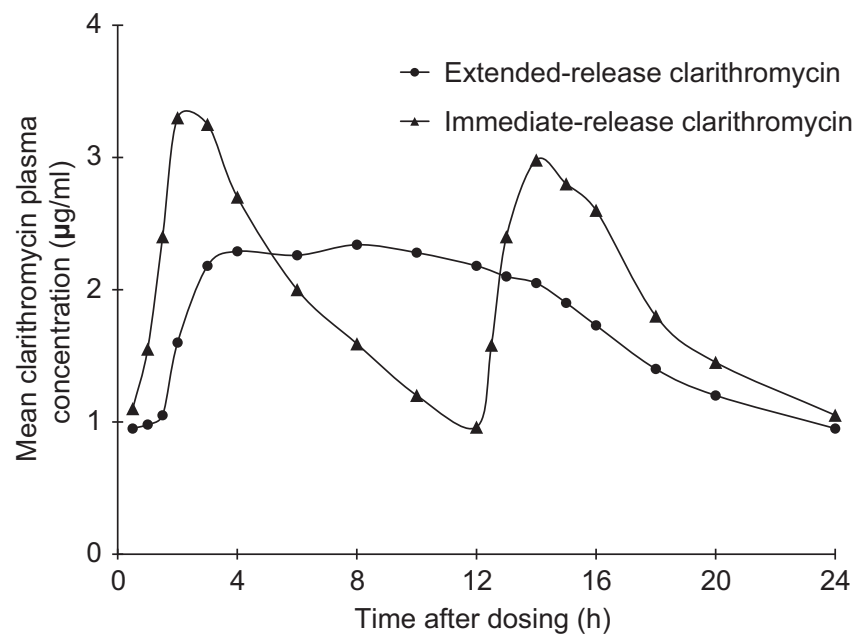

Figure 1 Steady-state clarithromycin plasma concentration time profiles. Adapted from reference 9. nanotechnology, researches on nanoparticle-based antibiotic delivery system may become a trend.

Therefore, sustained-release preparation has a primary important role in the antibiotic delivery field. In the past few years, great progress in extended-release formulations for antimicrobial drugs has been achieved. One of the driving factors for the advances is the development of slow-releasing materials. This review provides an overview of the novel formulation materials that are introduced into antimicrobial modified release delivery system and the existing materials are also summarized here.

\section{MATERIALS USED IN SUSTAINED-RELEASE PREPARATIONS FOR ANTIBIOTIC DELIVERY}

Although the development of sustained-release preparations is closely related to the update of equipment and processes, the development and application of new materials have a key role. Introducing more appropriate materials into drug-delivery systems can promote the clinical outcomes of drugs, further bringing in economic and social effects. According to the mechanism underlying the prolonged action, the materials can be divided into two major categories: matrix materials and coating materials. In addition, the complex formations are also imported as carriers for the retarded release of antibiotics.

\section{Matrix materials}

Matrix system is the simplest and the most cost-effective method to fabricate an extended-release dosage form and it is easy to produce on an industrial scale in conventional equipment. In the matrix system, the drug is combined and made into granules with excipients that alter the release rate of the drug. According to the materials used, the matrix systems have different mechanisms toward the controlled action. The most commonly used matrix materials are swellable hydrophilic materials. Once they are exposed to an aqueous medium, a successive progress of hydration of the polymer, gel formation on the surface of the polymer and subsequent continuous release of drug is followed. Another group of matrix materials is biodegradable materials. By embedding the drug in the slowly eroding matrix materials that erode in body fluids, the progressive release of the drug is realized. For the matrix materials that retain their shape during their passage through the alimentary tract, the drug is slowly released from the matrix by diffusion. In addition, a mucoadhesive drug-delivery system can prolong the residence time of drugs at the site of absorption or application, and thus extend the absorption time.

\section{Hydrophilic matrix materials}

Hydrophilic matrix system has enjoyed widespread attention and application in sustained-release delivery system owing to its excellent uniformity and ease of manufacture. The matrix can be obtained either by direct compression of the blend or from a wet granulation containing the active ingredient and hydrophilic carriers. Among all the hydrophilic materials, cellulosic polymers are probably used most frequently, such as hydroxypropylmethylcellulose, methylcellulose, hydroxypropylcellulose, hydroxyethylcellulose and sodium carboxymethylcellulose. Other non-cellulosic hydrophilic materials include gum/polysaccharides (for example, sodium alginate, xanthan gum, carrageenan, locust bean gum, chitosan, guar gum, pectin and crosslinked high amylase starch), polyethylene oxide, homopolymers and copolymer of acrylic acid. These materials are commonly used for the fabrication of matrices either alone or in conjugation.

Generally speaking, matrix materials with fast polymer hydration ability are preferable in hydrophilic matrix formulations. Otherwise, premature diffusion and disintegration may occur, especially for 
Table 1 Examples of antibiotics formulated as sustained-release delivery system

\begin{tabular}{|c|c|c|c|c|c|c|}
\hline $\begin{array}{l}\text { Antibiotic } \\
\text { category }\end{array}$ & Drug & $\begin{array}{l}\text { Brand } \\
\text { name drug }\end{array}$ & $\begin{array}{l}\text { Manufacturer/date } \\
\text { of approval }\end{array}$ & $\begin{array}{l}\text { Sustained-release technology and mate- } \\
\text { rials used in the products }\end{array}$ & $\begin{array}{l}\text { Extended release }(E R) \text { vs conventional } \\
\text { formulations or immediate-release (IR) } \\
\text { formulations }\end{array}$ & Reference \\
\hline \multirow[t]{5}{*}{$\begin{array}{l}\text { Time- } \\
\text { dependent } \\
\text { antibiotic }\end{array}$} & Amoxicillin & $\begin{array}{l}\text { Moxatag } \\
\text { tablets }\end{array}$ & $\begin{array}{l}\text { MiddleBrook } \\
\text { Pharmaceuticals/ } \\
23 \text { January } 2008\end{array}$ & $\begin{array}{l}\text { The tablet contains an immediate- } \\
\text { release granulation ( } 45 \% \text { of the dose) } \\
\text { and two delayed-release pellets, Pulse } 2 \\
\text { ( } 30 \% \text { of the dose) and Pulse } 3 \text { ( } 25 \% \text { of } \\
\text { the dose). The delayed-release pellets } \\
\text { release amoxicillin in a different region } \\
\text { of the intestinal tract subsequent to } \\
\text { reaching the pH trigger for each of the } \\
\text { respective film coats. }\end{array}$ & $\begin{array}{l}\text { Longer } \mathrm{T}>\mathrm{MIC} \text { than amoxicillin sus- } \\
\text { pension }(13.3 \mathrm{~h} \text { vs } 11.7 \mathrm{~h})\end{array}$ & 13 \\
\hline & $\begin{array}{l}\text { Amoxicillin/ } \\
\text { clavulanate } \\
\text { potassium }\end{array}$ & $\begin{array}{l}\text { Augmentin } \\
\text { XR tablets }\end{array}$ & $\begin{array}{l}\text { GlaxoSmithKline/ } \\
25 \text { September } \\
2002\end{array}$ & $\begin{array}{l}\text { The tablet consists of a bilayer tablet, } \\
\text { with one layer containing immediate- } \\
\text { release amoxicillin trihydrate ( } 56 \% \text { of } \\
\text { the dose) and clavulanic acid, and the } \\
\text { other layer containing sustained-release } \\
\text { sodium amoxicillin ( } 44 \% \text { of the dose). } \\
\text { The main inactive ingredient is } \\
\text { hypromellose. }\end{array}$ & $\begin{array}{l}\text { (1) Higher rate of treatment success } \\
\text { (2) Lower treatment cost }\end{array}$ & 8 \\
\hline & Clarithromycin & $\begin{array}{l}\text { Biaxin ER } \\
\text { tablets }\end{array}$ & $\begin{array}{l}\text { Abbott/6 August } \\
2001\end{array}$ & $\begin{array}{l}\text { The tablets are formulated using a } \\
\text { patented polymer-based matrix that } \\
\text { slows the release and extends absorption } \\
\text { from the gastrointestinal tract. The } \\
\text { polymer is a water-soluble hydrophilic } \\
\text { polymer. More preferably, the polymer } \\
\text { is hydroxypropylmethyl cellulose. }\end{array}$ & $\begin{array}{l}\text { (1) Improved patient compliance } \\
\text { (2) Enhanced gastrointestinal tolerabil- } \\
\text { ity and improved taste profile }\end{array}$ & 9,14 \\
\hline & Cefaclor & $\begin{array}{l}\text { Ceclor CD } \\
\text { tablets }\end{array}$ & Eli Lilly/June 1996 & $\begin{array}{l}\text { The delivery system has a slower rate } \\
\text { of dissolution owing to the hydrophilic } \\
\text { polymer that forms a gel layer on contact } \\
\text { with gastrointestinal fluids independent } \\
\text { of } \mathrm{pH} \text {. }\end{array}$ & $\begin{array}{l}\text { (1) Shorter regimen } \\
\text { (2) Lower and later steady-state peak } \\
\text { plasma concentrations }\end{array}$ & 15 \\
\hline & $\begin{array}{l}\text { Minocycline } \\
\text { hydrochloride }\end{array}$ & $\begin{array}{l}\text { Solodyn ER } \\
\text { tablets }\end{array}$ & $\begin{array}{l}\text { Medicis } \\
\text { Pharmaceutical/8 } \\
\text { May } 2006\end{array}$ & $\begin{array}{l}\text { The tablet contains hypromellose type } \\
2910 \text { and carnauba wax as the matrix } \\
\text { materials. }\end{array}$ & $\begin{array}{l}\text { (1) Reduced dose-related adverse events } \\
\text { and inflammatory lesions } \\
\text { (2) Improved therapeutic effect }\end{array}$ & 16 \\
\hline \multirow[t]{4}{*}{$\begin{array}{l}\text { Concentra- } \\
\text { tion-depen- } \\
\text { dent anti- } \\
\text { biotic }\end{array}$} & Ciprofloxacin & $\begin{array}{l}\text { Cipro XR or } \\
\text { Cipro XL } \\
\text { tablets }\end{array}$ & $\begin{array}{l}\text { Bayer/16 December } \\
2002\end{array}$ & $\begin{array}{l}\text { The bilayer tablet contains two different } \\
\text { salts of ciprofloxacin and consists of an } \\
\text { immediate-release component ( } 35 \% \text { of } \\
\text { the dose) and an erosion-matrix type } \\
\text { controlled-release component ( } 65 \% \text { of } \\
\text { the dose). }\end{array}$ & $\begin{array}{l}\text { (1) Higher } \mathrm{C}_{\max } \text { ( } 150-160 \% \text { higher) } \\
\text { with less interpatient variability (coeffi- } \\
\text { cient of variation: ER } 29.5 \% \text { vs IR } \\
78.8 \% \text { ) } \\
\text { (2) Improved patients' adherence to } \\
\text { therapy }\end{array}$ & 11 \\
\hline & $\begin{array}{l}\text { Ciprofloxacin } \\
\text { hydrochloride }\end{array}$ & $\begin{array}{l}\text { Proquin XR } \\
\text { tablets }\end{array}$ & $\begin{array}{l}\text { Esprit Pharma/19 } \\
\text { May } 2005\end{array}$ & & & \\
\hline & Azithromycin & $\begin{array}{l}\text { Zmax for } \\
\text { oral sus- } \\
\text { pension }\end{array}$ & $\begin{array}{l}\text { Pfizer/13 June } \\
2005\end{array}$ & $\begin{array}{l}\text { Prolonged action of the drug is obtained } \\
\text { via diffusion through pores formed in the } \\
\text { microspheres, and most of the drug is } \\
\text { released in the lower gastrointestinal } \\
\text { tract. }\end{array}$ & Improved compliance and convenience & 1 \\
\hline & Amikacin & $\begin{array}{l}\text { Arikace } \\
\text { (liposomal } \\
\text { amikacin } \\
\text { for inhala- } \\
\text { tion) }\end{array}$ & $\begin{array}{l}\text { Transave/August } \\
2011 \text { (start date of } \\
\text { phase III clinical } \\
\text { trial) }\end{array}$ & $\begin{array}{l}\text { The liposomes comprise the saturated } \\
\text { lipid dipalmitoyl phosphatidylcholine } \\
\text { and cholesterol via a proprietary } \\
\text { manufacturing process. }\end{array}$ & $\begin{array}{l}\text { Significant and sustained improvement } \\
\text { in lung function and reduction in } \\
\text { Pseudomonas density }\end{array}$ & 17 \\
\hline
\end{tabular}

water-soluble drugs, because of fast penetration of water. The initial burst effect for highly water-soluble drugs is often incontrollable and potentially unsafe in drug-delivery applications. The burst can be suppressed by insoluble coating or by modifying the excipients into suitable viscosity and chemistry. For instance, poly(2-hydroxyethyl methacrylate) (pHEMA), an extensively used hydrogel, showed an initial 'burst release' when used in controlled-release systems. To counter this intrinsic burst release and achieve a sustained release, the pHEMA surface was modified with octadecyl isocyanate to form a dense, hydrophobic brush coating. This surface modification created a rate-limiting barrier for molecular transport into and out of the polymer matrix, modulating hydration and controlling drug delivery, 
and hence the near zero-order release of norfloxacin from the matrix was obtained. ${ }^{18}$

The most common adverse event of antibiotics (for example, macrolides) is gastrointestinal (GI) stimulus that appears to be dose related; therefore, bypassing the absorption site in the upper GI tract is necessary especially in sustained-release preparations with larger dosage. It is known that variations of $\mathrm{pH}$ occur at GI tract, and hence application the $\mathrm{pH}$-responsive carriers may be a solution. Nonionic hydrophilic polymers such as cellulose ether exhibit pH-independent drug-release profiles, whereas there are $\mathrm{pH}$-responsive hydrogels composed of polymeric backbones with ionic pendant groups. The commonly studied $\mathrm{pH}$-responsive polymers include synthetic polymers such as poly(acrylamide), poly(acrylic acid), poly(methacrylic acid), poly(diethylaminoethyl methacrylate) and poly (dimethylaminoethyl methacrylate), and natural polymers such as albumin and gelatin. ${ }^{19}$ For instance, owing to the nature of sol-togel transition upon changes in $\mathrm{pH}$, alginates polymers and carbopol were used to deliver ciprofloxacin, and then the antimicrobial efficiency test proved that the formulation prolonged the antimicrobial effect of ciprofloxacin. ${ }^{20}$ However, all these environment-sensitive hydrogels have a significant weakness; that is, their response time is too slow. Hence, it is necessary to develop fast-acting hydrogels with enough mechanical strength.

\section{Biodegradable materials}

In this system, the release of drugs from the matrix mainly depends on the degradation of the matrix materials and diffusion of drugs from the polymers. Biodegradable materials used in sustained-release formulations can serve as matrix materials, microsphere and implants carriers. Biodegradable polymers include two categories: natural (for example, hemaleucin, gelatin) and synthetic polymers (for example, polyesters, polyorthoesters, polyalkyl $\alpha$-cyanoacrylate, polyamino acid). These materials can be hydrolyzed or degraded by enzymes in the physiological environment, and eventually absorbed or metabolized to water. Their biocompatibility and non-allergenic immunogenicity make them good application prospects in drug-delivery systems. As shown in Table 2, many biodegradable materials have been used to deliver antibiotics and have exhibited good activities.

Naturally derived materials have the advantage of similarity to extracellular matrix, excellent biocompatibility and easy surface modification. Nevertheless, their application is limited by inadequate mechanical properties and processability. ${ }^{21}$ For this reason, natural materials are often surface modified or used with other materials. One of the most commonly used material is chitosan, a copolymer of $\mathrm{N}$-acetylglucosamine and glucosamine derived from chitin, which has been included in European Pharmacopoeia and US Pharmacopeia. Owing to its biocompatibility, mucoadhesion and permeation-enhancing properties, chitosan has extensive applications in the medical field. More than a drug carrier for antibiotics delivery, chitosan has been demonstrated to possess a wide spectrum of antimicrobial activity and high killing rate against Gram-positive and Gram-negative bacteria, but lower toxicity toward mammalian cells. They may be incorporated into fibers, membranes or hydrogels, and used for contact disinfectants in many biomedical applications, including wound dressing, orthopedic tissue engineering, drug-delivery carrier and hemodialysis. ${ }^{22}$ Chitosan has its distinct superiority for antibiotic delivery, yet its application is restricted because of the solubility in weak acid solutions. Chitosan microspheres were optimized for higher acid resistance by the virtue of being crosslinked with pentasodium tripolyphosphate through two different microencapsulation procedures. The crosslinked microspheres were not only more stable in simulated gastric fluid, but also slower in the release of ampicillin. ${ }^{23}$

Different from natural materials, synthetic polymers show good mechanical properties and mass production potential with high reproducibility. Synthetic biodegradable polymers have been used in various administration routes. In addition, some multifunctional

Table 2 Examples of hydrophilic and biodegradable polymers used in antibiotics sustained-release preparations

\begin{tabular}{|c|c|c|c|c|}
\hline Material and formulation & Drug & $\begin{array}{l}\text { Targeted microorganism or } \\
\text { disease }\end{array}$ & Activity & Reference \\
\hline $\begin{array}{l}\text { Pentasodium tripolyphosphate crosslinked } \\
\text { chitosan microspheres }\end{array}$ & Ampicillin & Staphylococcus aureus & $\begin{array}{l}\text { (1) Higher acid resistance for ampicillin } \\
\text { (2) Slower but sustained release }\end{array}$ & 23 \\
\hline $\begin{array}{l}\text { Octadecyl isocyanate-coated pHEMA } \\
\text { (poly(2-hydroxyethyl methacrylate)) }\end{array}$ & Norfloxacin & $\begin{array}{l}\text { Staphylococcus } \\
\text { epidermidis }\end{array}$ & $\begin{array}{l}\text { Abolishing the initial burst release and allowing } \\
\text { a steady, sustained release }\end{array}$ & 18 \\
\hline $\begin{array}{l}\text { Carbopol and alginates polymers } \\
\text { in situ gelling systems }\end{array}$ & Ciprofloxacin & $\begin{array}{l}\text { Echerichia coli, } \\
\text { Staphylococcus strains, } \\
\text { Pseudomonas aeruginosa }\end{array}$ & $\begin{array}{l}\text { Prolonged antimicrobial effect and retained } \\
\text { properties against bacteria. }\end{array}$ & 20 \\
\hline $\begin{array}{l}\text { Injectable biodegradable polyurethane } \\
\text { scaffolds }\end{array}$ & Tobramycin & S. aureus & $\begin{array}{l}\text { (1) Providing structural templates } \\
\text { (2) Enhanced healing of infected fractures }\end{array}$ & 24 \\
\hline $\begin{array}{l}\text { Polyurethane scaffolds loaded with } \\
\text { hydrophobic vancomycin free base }\end{array}$ & Vancomycin & Infected bone defects & $\begin{array}{l}\text { (1) Served as structural templates } \\
\text { (2) Decreased burst release } \\
\text { (3) Improved infection control in vivo }\end{array}$ & 25 \\
\hline $\begin{array}{l}\text { Injectable and thermally responsive } \\
\text { polypeptide depots }\end{array}$ & $\begin{array}{l}\text { Cefazolin and } \\
\text { vancomycin }\end{array}$ & Orthopaedic infection & $\begin{array}{l}\text { (1) Deliver scaffolds via syringe injection } \\
\text { (2) Sustained release of antibiotics }\end{array}$ & 35 \\
\hline $\begin{array}{l}\text { Poly(trimethylene carbonate)-based surface } \\
\text { eroding system }\end{array}$ & $\begin{array}{l}\text { Gentamicin and } \\
\text { vancomycin }\end{array}$ & Bone infection & $\begin{array}{l}\text { (1) Without acidic degradation products } \\
\text { (2) Constant and easily controllable release rates }\end{array}$ & 27 \\
\hline $\begin{array}{l}\text { Poly-(DL-lactic-co-glycolic acid) matrix } \\
\text { wound dressing }\end{array}$ & $\begin{array}{l}\text { Ceftazidime } \\
\text { hydrate }\end{array}$ & $\begin{array}{l}P . \text { aeruginosa, Staphylococ- } \\
\text { cus albus }\end{array}$ & $\begin{array}{l}\text { (1) No cellular toxicity } \\
\text { (2) Showing a long-lasting antimicrobial effect }\end{array}$ & 36 \\
\hline $\begin{array}{l}\text { PHBV (poly(hydroxybutyrate -polyhydroxyva- } \\
\text { lerate)) and wollastonite composite } \\
\text { microspheres }\end{array}$ & Gentamicin & $\begin{array}{l}\text { Bone infection and bone } \\
\text { fillings }\end{array}$ & $\begin{array}{l}\text { Lower release rate and longer antimicrobial } \\
\text { activity compared with the pure PHBV micro- } \\
\text { spheres }\end{array}$ & 31 \\
\hline
\end{tabular}


materials can not only prolong the drug release, but also have an additional role in treatment. An instance was polyurethane, whose capacity of promoting new bone formation had been proved in vivo. Hafeman et al. ${ }^{24}$ verified the potential of polyurethane as injectable biodegradable polyurethane scaffold for long-term drug delivery. In spite of the prolonged action, the total release of antibiotics was greater than current clinical treatment poly(methyl methacrylate) (PMMA) beads. ${ }^{24}$ In another research, the porous polyurethane scaffold and the reduction of water solubility of vancomycin were combined to acquire a slower release. The decreased water solubility weakened the burst release and this was achieved by precipitating the hydrophilic vancomycin hydrochloride at $\mathrm{pH} 8$ for the free base form, which is more hydrophobic and less soluble. ${ }^{25}$

Biodegradable materials are ideal for the local treatment of infection because a second surgical intervention to remove the carrier is avoided. For the treatment of severe wound infection, lasting release of antibiotics lessens the frequent replacements that cause inconvenience and financial burden. Nevertheless, the most frequently investigated biodegradable materials such as poly(lactic acid) or poly(glycolic acid) produce acidic degradation products that may accumulate and become concentrated, leading to toxicity. ${ }^{26} \mathrm{~A}$ biocompatibility polymer poly(trimethylene carbonate) (PTMC) with no influence on the $\mathrm{pH}$ was explored. The surface erosion of PTMC occurred only in the presence of lipase and thus provided constant release of the antibiotics. ${ }^{27}$ Materials degraded by enzymes hold promise for antibiotic-modified release. Dave et al. ${ }^{28}$ have reported biocatalytic-based antimicrobial coatings. In the research, the sustained release of gentamicin sulfate was controlled by the degradation of the polycaprolactone (PCL), whereas the latter was controlled by the enzyme concentration. ${ }^{28}$

One of the important utilization for synthetic polymers is biodegradable microsphere. Microsphere technology is an established technique that is successful in offering long-lasting effects of agents. Depending on the physicochemical properties of encapsulated drugs and polymeric excipients, microspheres can be programmed for content release by diffusion or erosion, or a combination of both. Materials that have come into wide use and those that generated the most profit for microspheres seem to be the aliphatic poly(esters) such as poly(lactide) (PLA), poly(glycolide) (PGA) and especially the copolymer of lactide and glycolide poly(lactide-co-glycolide) (PLGA). ${ }^{29}$ An important feature of this class of polymers is that it is widely approved by the FDA (Food and Drug Administration). Polymeric microspheres are attractive because of their biocompatibility, biodegradability and capability of encapsulating various drugs via both oral and injection route. However, it is difficult to manufacture microspheres in large quantities and maintain drug stability as well.

By the combination of two or more materials, the extended-release delivery system can offer the advantage of facilitated adjustment of desired drug-release patterns, mechanical properties and drug release mechanisms. ${ }^{30}$ However, the system based on polymer blend is more complex than that of single polymer; for example, the polymer mixture can be incompatible, and aqueous polymer dispersions might flocculate during long-term storage. For this reason, more attention has to be paid when using this type of formulation. Composite microspheres combined with bioactive wollastonite with biodegradable poly(hydroxybutyrate-polyhydroxyvalerate) (PHBV) showed much lower release rate of gentamicin than the pure PBHV microspheres, which was credited to the formation of apatite layer on their surface. ${ }^{31}$ an additional study showed that when the wollastonite was used in vivo, an apatite layer was formed by which the new bone tissue bonded to the implant. ${ }^{32}$ Thence, the chemical fixation of biomaterials to bone tissue and ultimately in vivo success of the bone grafting materials was facilitated. Besides, incorporation of microspheres into scaffolds can abolish the initial burst by a combination of pore diffusion and polymer erosion. ${ }^{33,34}$

\section{Bioadhesive materials}

The objective of using mucoadhesive or bioadhesive controlled drug delivery system is to prolong their residence at a specific site of delivery, thus facilitating the drug absorption process. For mucoadhesive agent, first-pass metabolism in the liver and presystemic elimination in the GI tract is avoided as the mucosa is well supplied with both vascular and lymphatic drainage. The commonly used bioadhesive polymers include polyacrylic acid, cellulosic, polysaccharide and natural polymers such as acacia gum and alginic acid. Besides, high-molecular-weight polymers such as polyvinylpyrrolidone and poly(ethylene glycol) (PEG) also have the feature of bioadhesion. Carbomer, one of the most commonly used materials of bioadhesion, can adhere strongly to mucosal membranes without causing irritation. Carbomer and hydroxypropylmethylcellulose were used to swell and form a gel adhering to the mucosa, and a prolonged action for antibiotics into the oral cavity was obtained. ${ }^{37,38}$

As a carrier, mucoadhesive improves drug delivery by various routes of administration, for example, oral, buccal, nasal, ocular, vaginal and rectal, either for systemic or for local effects. For the delivery of antibiotics, oral cavity and stomach are the most attractive mucoadhesive sites because dental diseases are regarded as one of the most common diseases afflicting mankind throughout the world, and Helicobacter pylori infection is believed to be the main pathogenic factor in the development of peptic ulcer disease. For the treatment of periodontitis or peptic ulcer disease, system administration of antibiotics often causes a rapid decline of the plasma antibiotic concentration to subtherapeutic levels, thus developing microbial resistance. ${ }^{39}$ Hence, the delivery system that localizes the antibiotics at the site of infection to achieve sustained bactericidal concentrations is desirable.

On the gastric mucoadhesive dosage form, the heavy and bulky mucoadhesive tablet is apt to detach from the mucosa when traveling through the GI tract, which can be avoided by microspheres. Besides prolonging the residence time, mucoadhesive microspheres have additional advantages such as efficient absorption and enhanced bioavailability of the drugs, owing to a high surface-to-volume ratio and a much more intimate contact with the mucus layer. ${ }^{40}$ In addition, the stability of antibiotic in the low $\mathrm{pH}$ should be taken into account for gastric mucoadhesive formulation since some antibiotics such as benzylpenicillin, macrolides and tetracyclines are unstable in acid. Chitosan microspheres for gastric mucoadhesive administration have been prepared and demonstrated to increase bioavailability of clarithromycin and tetracycline. ${ }^{41,42}$ As gastric mucoadhesive carrier, chitosan is reported to have some advantages; that is, gel-forming ability at low $\mathrm{pH}$, antacid and antiulcer activities that prevent or weaken drug irritation in stomach, the ability to swell and expand in the acid medium and enhancement toward the penetration of molecules across mucosal surface. ${ }^{42}$

\section{Coating materials}

In the coating system, a drug-loaded core is coated with coating material solutions, dispersions or even organic solvents. This system is considered as a reservoir system and the extended release of the drug is realized by diffusion. Therefore, the permeability of the membrane materials is directly related to the body fluid penetration and the 
release rate of drugs can be regulated by the variation in the thickness of the coatings. To optimize the drug release, pore formers that are less hydrophobic and allow opening channels in the membrane are often incorporated. Besides the film coating, novel polyelectrolyte multilayers have been developed as coatings for implantable devices.

Film coating materials. The film coatings broaden the application of tablets as they are prone to being prepared into gastric, enteric, slowrelease or targeting formulations. Many coating materials are polymers with high molecular weight and capable of retarding the release of a wide range of drugs, such as cellulose acetate, ethylcellulose, polyacrylic resin and polyethylene. For instance, ethylcellulose, the most commonly used sustained-release coating material, is insoluble in water and thus it can serve as a hydrophobic coating agent to modify the drug release. In recent years, aqueous polymer dispersions such as Aquacoat and Surelease have been extensively used for extended-release coating because of their high solid content, low coating viscosity, easy operation and coating uniformity. Other known polymers are those belonging to the Eudragit group that represent poly(meth)acrylates dispersion: Eudragit RL and RS polymers with alkaline are insoluble but permeable in digestive fluids and Eudragit NE polymers with neutral groups enable controlled time release of the active ingredient by $\mathrm{pH}$-independent swelling.

Protein and polypeptide-based drugs always need special attention on account of their rapid degradability and toxicity at high concentrations. Therefore, more tailored materials should be used. Collagen, which has good biocompatibility with an exceptional ligand encapsulating property, has been exploited as a film material for protein and polypeptide. Pexiganan, a 22-amino-acid peptide-based antimicrobial agent, was coated with different concentrations of collagen. The results revealed that $2.5 \% \mathrm{w} / \mathrm{w}$ of collagen film showed a maximum sustainable activity over $72 \mathrm{~h}$ with effective antimicrobial concentrations. ${ }^{43}$ By the utilization of collagen membrane, sustained release of peptidebased antimicrobial in infected wounds was probable. Sripriya et al ${ }^{44}$ prepared a collagen bilayer dressing containing ciprofloxacin. The investigation in vitro and in vivo suggested a sustained release of ciprofloxacin from the collagen bilayer dressing, and they were capable of serving as a dressing for an on-site delivery system. ${ }^{44}$

In addition to the system administration in tablets in dosage form, film coatings are also utilized in local administration. The ocular bioavailability of the conventional forms is low because of rapid, extensive precorneal loss and the eye physiological barriers. Consequently, frequent administration or highly concentrated solutions are required, which result in poor patient compliance. With the aid of contact lenses, sustained-release delivery system for ophthalmic administration has been developed to combine prolonged ophthalmic action with the ease of application. Many attempts of the delivery device have failed to achieve constant drug release, including conventional soft contact lenses, 'biomimetic' and molecularly imprinted hydrogel contact lenses. ${ }^{45-47}$ Ciolino et al. ${ }^{48}$ succeeded in delivering drugs to the eye with zero-order kinetics. The device they designed was a dual polymer system, with one polymer film PLGA containing the test compounds and the other polymer pHEMA used as a component of the contact lenses. The release pattern was a brief and minimal initial burst followed by a controlled release of ciprofloxacin with zeroorder release kinetics under infinite sink conditions for over 4 weeks. And the rate of drug release can be regulated by changing either the ratio of drug to PLGA or the molecular mass of the PLGA used. ${ }^{48}$

Catheters and other indwelling devices such as surgical implant placed inside the human body are prone to bacterial infection, thereby causing serious risk to patients. To circumvent and mitigate local infection for a long period, the surfaces of the graft or device are usually coated with antibiotic-containing composites. The silica sol-gel composites are novel controlled-release materials that are resorbable and biocompatible. ${ }^{49}$ Thin sol-gel films coating vancomycin on a Ti-alloy substrate were synthesized for the prevention and treatment of bone infections. The vancomycin-containing sol-gel film decreased profoundly the number of Staphylococcus aureus when evaluated in a rat osteomyelitis model. A close correlation between vancomycin release and sol-gel film degradation rates indicated that film degradation is the main mechanism underlying the control of release. ${ }^{50,51}$

Polyelectrolyte multilayer materials. Although many antimicrobial orthopedic implant coatings are developed, drug dosage or release rate cannot be easily tuned in most cases. Apart from the bacteria introduced during the surgical process, most often the implantassociated infections are ascribed to the attachment of bacteria in bloodstream. Thus, developing the antibiotics delivery system that discourages bacterial adhesion is imperative. Polyelectrolyte multilayers are proposed to overcome this disadvantage. With the development of layer-by-layer (LbL) deposition technique, polyelectrolyte multilayers were prepared. LbL deposition is a nanoscale polymer thin film formed by alternating deposition of polyelectrolytes or other multiply charged species on surface materials of any size and geometry. Polyelectrolyte multilayers using the LbL technology platform have demonstrated controlled erosion and tunable drug release in physiological buffers. In addition, by changing the number of deposited layers, encapsulated dosage can be readily and precisely tuned.

The LbL films are degraded via a hydrolytic mechanism that enables continuous elution of drugs without the need of enzymic or cellular interaction, and the degradation products were non-toxic. The top-down erosion principle of the film has a primary role against bacterial attachment. ${ }^{52}$

Polyelectrolyte multilayers incorporating gentamicin were fabricated using the LbL deposition process as a device coating to address an existing bone infection in a direct-implant exchange operation. The films eluted $\sim 70 \%$ gentamicin in vitro during the first 3 days and subsequently continued to release drug for more than 4 additional weeks. In the in vivo S. aureus bone infection model, the bactericidal ability of polyelectrolyte multilayers overwhelmingly surpassed uncoated devices..$^{53}$ Moreover, the multilayers are capable of incorporating and releasing different therapeutic agents with different release rates. Dual functional polyelectrolyte multilayers with a bolus delivery of gentamicin to eradicate infection and a retarded release of diclofenac to minimize foreign body response at implant site were prepared. ${ }^{54}$ The versatility and tunable release for drugs of these polyelectrolyte multilayers make them attractive as coatings for implantable devices.

\section{Complex materials}

When chemically or physically combined with certain other chemical agents, some drug molecules form complexes that may be slowly soluble in body fluids. This slow dissolution rate provides the extended release of the drug. Cyclodextrins (CDs) are unique molecules with cage structure providing a wide range of applications in the pharmaceutical field owing to their complex forming capability, which allows them to include hydrophobic molecules in their hydrophobic cavity and to mask the physicochemical properties of the guest molecule. ${ }^{55}$ For water-soluble drugs, hydrophobic CDs such as alkylated and acylated derivatives are useful as slow-release carriers. 
The use of such complexes always results in a biphasic release, immediate release because of the molecules unbound and subsequent delayed action as the drug molecules are progressively released by a complex dissociation mechanism. This is desirable for antibiotic delivery especially for graft infection. ${ }^{56}$ In addition, it is reported that CDs have the ability to increase the antimicrobial activity of cefdinir $^{57}$ and interact with ciprofloxacin. ${ }^{58}$

Vascular prostheses are widely used to replace or bypass damaged arteries. However, there is a high mortality rate for vascular prosthesis infections. ${ }^{59}$ Hence, vascular prostheses are always coated with antibiotics. Compared with only antibiotic-loaded vascular prostheses, antibiotic- $\beta-C D$ inclusion complexes exhibited a prolonged antimicrobial effect and more antibiotics could be loaded. Furthermore, the microbiological test showed better antimicrobial activity for complexcoated vascular prostheses, and also showed that a wide range of antibiotics can be included into CDs, which makes them potential for the treatment of multigerm vascular prostheses infections. ${ }^{56,60,61}$ Not only are CDs used alone as a carrier, but they are also incorporated into other carriers, such as bioactive glasses ${ }^{62}$ and polymers, ${ }^{63}$ to obtain an extended release.

On the basis of the fact that chemical bonds have lower energy like the van der Waals forces, ionic bonds and coordinate or chelate bonds, it should be possible to develop sustained-release system conceptually. Various small molecular bioactive agents have been bound via degradable covalent linkages to many different polymeric systems to control the release of the agents. ${ }^{64}$ For example, cellulose xanthatemetal-tetracycline complex was prepared to arrest the release of agents. Compared with a mixture of cellulose, metal and tetracycline, the tetracycline release from the cellulose-metal-tetracycline complexes was greatly sustained, which have been manifested by the antibacterial activity lasted for 7-22 days. ${ }^{65}$ In addition, formation of complex can modify the hydrophobicity of the drug, which also has an influence on the drug release. Gentamicin was assembled into a hydrophobic complex by hydrophobic ion pairing with the anionic surfactant bis(2-ethylhexyl) sulfosuccinate sodium salt (AOT). Compared with the gentamicin-loaded nanoparticles, the gentamicin-AOT complex moderated the initial high burst release. The reduction was attributed to the enhanced hydrophobicity, which may allow an increased retention of the drug on the nanoparticle surface. Besides, the low solubility of the gentamicin-AOT complex in aqueous environments could result in a slow diffusion of the drug through the polymeric matrix, and therefore, in a more sustained-release kinetic of the drug. ${ }^{66}$

\section{MATERIALS USED IN NANOPARTICLES FOR ANTIBIOTIC DELIVERY}

Over the past few decades, the applications of nanotechnology have been extensively explored in many medical areas, especially in drug delivery. One of the areas that have benefited from the advance is microbiology. A valuable review regarding the development of nanoparticles for antimicrobial drug delivery is by Zhang et al. ${ }^{67}$ Herein, we focus on the sustained-release role of nanoparticles for antibiotic delivery and materials used for the delivery. Owing to their ultrasmall size, nanoparticle formulations have many advantages over traditional dosage forms. As for the contribution to prolonged action of active agent, they are capable of improving serum solubility of the drugs, prolonging the systemic circulation lifetime and releasing drugs in a sustained and controlled manner. ${ }^{68,69}$ Moreover, antibiotic-loaded nanoparticles can enter host cells through endocytosis and then release drug payloads to treat microbe-induced intracellular infections. ${ }^{67}$ As the review of Zhang et al. ${ }^{67}$ has covered a wide field of liposomes, solid lipid nanoparticles and dendrimers for antimicrobial drug delivery, here we only summarize polymers and inorganic materials used in nanoparticles.

\section{Polymers}

Many biocompatible and biodegradable polymers and their derivates have been used as antibiotic nanocarriers to retain longer antimicrobial effect. Among them, amphiphilic polymers have received increasing attention because they can form self-assemblies composed of hydrophilic regions of the molecules in contact with surrounding solvent and the hydrophobic tail in the center. The hydrophobic cores can serve as reservoirs to trap hydrophobic drugs and gene for extended action. In addition, reducing toxic side effects and improving therapeutic effects also make amphiphiles attractive. $^{70}$ Amphiphilic polymers include PLA, PGA, PLGA, PCL and poly(cyanoacrylate) (PCA). As the amphiphile should be biodegradable and non-toxic, much attention has been paid to natural biomaterials, of which chitosans were studied frequently. Various hydrophobic modifications have been made for chitosans to enable them to form nanosized self-aggregates, and some of them show promise as carriers for hydrophobic drugs. ${ }^{70-72}$ Longer hydrophobic chains and bigger hydrophobic groups benefit the stabilization of the micelle structure and the protection for drug compounds from the environment. Oleoyl-chitosan self-assembled nanoparticles loaded with doxorubicin were reported obviously superior to doxorubicin solution, and the blank nanoparticles showed no cytotoxicity to mouse embryo fibroblasts. Meanwhile, the nanoparticles exhibited a sustained release after a burst release at phosphate-buffered saline $(\mathrm{pH} 7.4) .{ }^{73}$

As the anomalies of temperature are common and important signs of various diseases, especially for bacterial infection, temperatureresponsive polymers have become increasingly attractive as carriers for the controlled drug-delivery systems. In addition, the controlled release of drugs can also be achieved by the exertion of the local thermal field in vitro. The thermo-sensitive polymers can protect drugs or bioactive molecules away from denaturing aggregation and undesired chemical reactions under the low temperature condition. When temperature exceeds the gelling temperature, the loaded drugs or bioactive molecules can be released in a controlled manner. For antibiotic delivery, temperature-response technology can be applied into local infections such as osteomyelitis. A biodegradable thermosensitive implant composed of poly(ethylene glycol) monomethyl ether (mPEG) and PLGA copolymer (mPEG-PLGA) as a sol-gel drug-delivery system for treating bone infection was prepared. The release of teicoplanin from the formulation showed near-linear profile and lasted up to 4 weeks. In vivo study confirmed that the sustained release of teicoplanin from mPEG-PLGA hydrogel could efficiently treat the osteomyelitis in rabbits without the disadvantages of PMMA cement beads. $^{74}$

Nanoparticle with positive charge is an effective strategy to prolong mucosa residence time and continuously release the drugs. As epithelial cells in the various tissues, including GI tract, carry negative charges on their surface, the positively charged particles can strongly interact with epithelia. ${ }^{75}$ Accordingly, it is anticipated that positively charged delivery systems can lead to extended residence time. The longer absorption time will ultimately result in better bioavailability of the drugs. Positively charged Eudragit RS100 and RL100 polymer nanoparticles have been reported to extend the release of antibiotics. ${ }^{76,77}$ In addition, PLGA nanoparticles prepared by lyophilized nanoprecipitation technique were confirmed to be capable of improving precorneal residence time and ocular penetration so as to 
extend the release of antibiotics with a longer shelf life than conventional marketed formulations ${ }^{78,79}$

Many other polymeric nanoparticles have also been studied for various applications. A micron-scale porous particle filled with selfassembled rifampicin nanoparticles was served as aerosol formulations. It received extended-release profile in vitro and guinea pigs. ${ }^{80}$ Polymeric micelles self-assembled from cholesterol-conjugated PEG successfully delivered ciprofloxacin across the blood-brain barrier (BBB) after being anchored with transcriptional activator TAT peptide. ${ }^{81}$ Plasma half-life of three antitubercular drugs encapsulated within wheatgerm agglutinin-coated PLGA nanoparticles are significantly longer than uncoated PLGA nanoparticles upon oral/inhalation routes in mice because of lectins that can be recognized by glycosylated structures in the gut and the lung mucosa. ${ }^{82}$ Examples of polymeric nanoparticles for antibiotics sustained release are listed in Table 3.

\section{Inorganic materials}

Unlike organic nanoparticles such as liposomes and polymeric nanoparticles that commonly serve as drug carriers only, inorganic nanoparticles often exhibit multiple functions in medicine; for example, as filling materials for their good mechanical properties. Prevention and treatment of osteomyelitis, periodontitis and infections associated with orthopedic implant surgery have been the central issue in the antimicrobial field. In the treatment of such infections, the delivery of active antimicrobial agents directly to the site of infection have gradually taken the place of systemic administration which usually purports long-term administration at high dosage. Hydroxyapatite has been used as a drug carrier because its chemical composition is similar to the bone and teeth mineral phase and rigidity properties. Meanwhile, hydroxyapatite has been applied for the sustained release and long-term delivery of various chemicals, anticancer drugs and antibiotics.

With improved biocompatibility and mechanical properties of bone grafting materials, compared with hydroxyapatite, nanohydroxyapatite has gained increasing attention. A novel injectable drug-delivery system, nanohydroxyapatite microsphere, has been developed for periodontitis treatment. A long-term sustained release was achieved subsequent to a fast initial release, which made these systems good alternatives for antibiotic delivery. Besides, the delivery systems could provide a fourfold beneficial effect if the sustained-release profile combined with the osteoconduction, resorbability and potential use as injectable bone-filling material of porous hydroxyapatite microspheres. ${ }^{85}$ Other studies have found that nanohydroxyapatite scaffold contained antibacterials that were capable of realizing bone regeneration together with antimicrobial properties. ${ }^{86,87}$

Other nanocomposites such as biomimetic apatite, calcium sulfate and resorbable silica-calcium phosphate also exhibited an extended release. The calcium sulfate-biomimetic apatite nanocrystalline component released cephalexin and gentamicin through a combined mechanism, the major drug diffusion through the matrix and the minor matrix dissolution. ${ }^{88}$ A porous bioactive resorbable silicacalcium phosphate nanocomposite was synthesized that can provide a sustained release of effective dose of gentamicin for 28 days. The release pattern, initial burst release followed by a sustained release, indicated that the nanocomposite was a appropriate delivery vehicle for osteomyelitis and regenerate bone treatment. ${ }^{89}$

\section{DISCUSSION AND OUTLOOK}

Over the past several years, many progresses in extended-release field have been achieved and new antibiotic sustained-release formulations have constantly come into the market. Most of the preparations are hydrophilic matrix delivery systems because of their ease of manufacture and excellent uniformity. Furthermore, the applications of new materials have optimized these delivery systems. Among them, biodegradable materials that include naturally derived materials (for example, chitosan and collagen) and synthetic polymers (for example, polyurethane, PHBV and pHEMA) have shown potential for clinical availability owing to their low toxicity, biodegradability and

Table 3 Examples of polymeric materials used in antibiotics nanoparticles

\begin{tabular}{|c|c|c|c|c|}
\hline Material and formulation & Drug & $\begin{array}{l}\text { Targeted microorganism } \\
\text { or disease }\end{array}$ & Activity & Reference \\
\hline $\begin{array}{l}\text { Porous particle containing PLGA } \\
\text { nanoparticles }\end{array}$ & Rifampicin & Mycobacterium tuberculosis & $\begin{array}{l}\text { Effective dispersibility and longer plasma con- } \\
\text { centration }\end{array}$ & 80 \\
\hline Oleoyl-chitosan nanoparticles & Doxorubicin & Cancer cells & $\begin{array}{l}\text { (1) High encapsulation efficiency } \\
\text { (2) Enhanced therapeutic effect }\end{array}$ & 73 \\
\hline TAT-PEG-cholesterol micelles & Ciprofloxacin & Brain infection & $\begin{array}{l}\text { (1) Across the BBB } \\
\text { (2) Prolonged the antibiotic release }\end{array}$ & 81 \\
\hline PCL and PLGA nanoparticles & Levofloxacin & Escherichia coli & $\begin{array}{l}\text { Inhibiting the biofilm growth and reduced anti- } \\
\text { biotic tolerance }\end{array}$ & 83 \\
\hline PLGA nanoparticles & Gentamicin & Brucellosis & Carrying antibiotic through cellular membranes & 84 \\
\hline $\begin{array}{l}\text { Wheatgerm agglutinin-coated PLGA } \\
\text { nanoparticles }\end{array}$ & Rifampicin & Tuberculosis & $\begin{array}{l}\text { (1) Prolonged plasma drug level } \\
\text { (2) Increased relative bioavailability }\end{array}$ & 82 \\
\hline $\begin{array}{l}\text { mPEG-PLGA copolymer nanoparticles } \\
\text { as a sol-gel delivery system }\end{array}$ & Teicoplanin & Osteomyelitis & $\begin{array}{l}\text { (1) Easy preparation, } 100 \% \text { encapsulated rate } \\
\text { (2) Injectable and in situ gelling } \\
\text { (3) Sustained release of drugs }\end{array}$ & 74 \\
\hline $\begin{array}{l}\text { Positively charged Eudragit RS100 and } \\
\text { RL100 nanoparticles }\end{array}$ & $\begin{array}{l}\text { Ciprofloxacin, } \\
\text { amphotericin-B }\end{array}$ & $\begin{array}{l}\text { Pseudomonas aeruginosa, } \\
\text { Staphylococcus aureus, } \\
\text { Fusarium solani }\end{array}$ & $\begin{array}{l}\text { (1) A prolong drug release } \\
\text { (2) No eye irritation }\end{array}$ & 76,77 \\
\hline PLGA nanoparticles & $\begin{array}{l}\text { Sparfloxacin, } \\
\text { Levofloxacin }\end{array}$ & P. aeruginosa, S. aureus & $\begin{array}{l}\text { (1) Improved precorneal residence time and } \\
\text { ocular penetration } \\
\text { (2) Good shelf life }\end{array}$ & 78,79 \\
\hline
\end{tabular}

Abbreviations: BBB, blood-brain barrier; mPEG, poly(ethylene glycol) monomethyl ether; PCL, polycaprolactone; PEG, poly(ethylene glycol); PLGA, poly(lactide-co-glycolide). 
multifunction for antibiotic delivery. In addition, materials that are obtained by chemically modifying the existing materials or combining different carriers in physical mixtures are more tailored for the slow release of antibiotics, yet their complexity and long-term stability should be taken into consideration.

In spite of the progress achieved in conventional delivery, increasing attention has been paid to the nanoparticles whose main advantage lies in their ultrasmall size and long circulation characteristics. However, until now, only few nanoparticle-based antimicrobial agents have been approved for clinical use. The limitation of their application is mainly caused by the high cost and unsatisfactory drug loading. These shortcomings may be overcome by the development of polymers (for example, amphiphilic polymers) and inorganic porous materials. As Arikace has thrown light on the nanoparticle-based extended-release antibiotic delivery, we anticipate that more antibiotic nanoparticle products will come to sight in the future.

1 Blasi, F., Aliberti, S. \& Tarsia, P. Clinical applications of azithromycin microspheres in respiratory tract infections. Int. J. Nanomedicine 2, 551-559 (2007).

2 Jacobs, M. R. Optimisation of antimicrobial therapy using pharmacokinetic and pharmacodynamic parameters. Clin. Microbiol. Infect. 7, 589-596 (2001).

3 Drusano, G. L. Role of pharmacokinetics in the outcome of infections. Antimicrob. Agents Chemother. 32, 289-297 (1988).

4 Turnidge, J. D. The pharmacodynamics of beta-lactams. Clin. Infect. Dis. 27, 10-22 (1998).

5 Roberts, J. A., Lipman, J., Blot, S. \& Rello, J. Better outcomes through continuous infusion of time-dependent antibiotics to critically ill patients? Curr. Opin. Crit. Care 14, 390-396 (2008).

6 Roberts, J. A., Paratz, J., Paratz, E., Krueger, W. A. \& Lipman, J. Continuous infusion of beta-lactam antibiotics in severe infections: a review of its role. Int. J. Antimicrob. Agents 30, 11-18 (2007).

7 Moriyama, B., Henning, S. A., Neuhauser, M. M., Danner, R. L. \& Walsh, T. J. Continuous-infusion beta-lactam antibiotics during continuous venovenous hemofiltration for the treatment of resistant gram-negative bacteria. Ann. Pharmacother. 43, 1324-1337 (2009)

8 Jackson, J., Fernandes, A. W. \& Nelson, W. A naturalistic comparison of amoxicillin/ clavulanate extended release versus immediate release in the treatment of acute bacterial sinusitis in adults: a retrospective data analysis. Clin. Ther. 28, 1462-1471 (2006).

9 Gotfried, M. H. Clarithromycin (Biaxin) extended-release tablet: a therapeutic review. Expert Rev. Anti. Infect. Ther. 1, 9-20 (2003).

10 Thomas, J. K. et al. Pharmacodynamic evaluation of factors associated with the development of bacterial resistance in acutely ill patients during therapy. Antimicrob. Agents Chemother. 42, 521-527 (1998).

11 Talan, D. A., Naber, K. G., Palou, J. \& Elkharrat, D. Extended-release ciprofloxacin (Cipro XR) for treatment of urinary tract infections. Int. J. Antimicrob. Agents (23 Suppl 1), S54-66 (2004).

12 Insmed. Arikace ${ }^{\mathrm{TM}}$ for Nontuberculous Mycobacteria. Insmed, City, (2011).

13 Robertson, S. Amoxicillin clinpharm pediatric review. City, (2007).

14 Alrazzak, L. A., Crampton, S. L., Gustavson, L. E., Hui, H., Milman, N. \& Semla, S. Extended release formulations of clarithromycin. City, (2004).

15 Meyers, B. R. Cefaclor revisited. Clin. Ther. 22, 154-166 (2000).

16 Fleischer, A. B. Jr.,, Dinehart, S., Stough, D. \& Plott, R. T. Safety and efficacy of a new extended-release formulation of minocycline. Cutis 78, 21-31 (2006).

17 Meers, P. et al. Biofilm penetration, triggered release and in vivo activity of inhaled liposomal amikacin in chronic Pseudomonas aeruginosa lung infections. J. Antimicrob. Chemother. 61, 859-868 (2008).

18 Anderson, E. M. et al. Sustained release of antibiotic from poly(2-hydroxyethyl methacrylate) to prevent blinding infections after cataract surgery. Biomaterials $\mathbf{3 0}$ 5675-5681 (2009).

19 Gupta, P., Vermani, K. \& Garg, S. Hydrogels: from controlled release to pH-responsive drug delivery. Drug Discov. Today 7, 569-579 (2002).

20 Al-Kassas, R. S. \& El-Khatib, M. M. Ophthalmic controlled release in situ gelling systems for ciprofloxacin based on polymeric carriers. Drug Deliv. 16, 145-152 (2009).

21 Huang, S. \& Fu, X. Naturally derived materials-based cell and drug delivery systems in skin regeneration. J. Control. Release 142, 149-159 (2010).

22 Kong, M., Chen, X. G., Xing, K. \& Park, H. J. Antimicrobial properties of chitosan and mode of action: a state of the art review. Int. J. Food Microbiol. 144, 51-63 (2010).

23 Anal, A. K., Stevens, W. F. \& Remunan-Lopez, C. Ionotropic cross-linked chitosan microspheres for controlled release of ampicillin. Int. J. Pharm. 312, 166-173 (2006).

24 Hafeman, A. E. et al. Local delivery of tobramycin from injectable biodegradable polyurethane scaffolds. J. Biomater. Sci. Polym. Ed. 21, 95-112 (2010).
25 Li, B., Brown, K. V., Wenke, J. C. \& Guelcher, S. A. Sustained release of vancomycin from polyurethane scaffolds inhibits infection of bone wounds in a rat femoral segmental defect model. J. Control. Release 145, 221-230 (2010).

26 Taylor, M. S., Daniels, A. U., Andriano, K. P. \& Heller, J. Six bioabsorbable polymers: in vitro acute toxicity of accumulated degradation products. J. Appl. Biomater. 5, 151-157 (1994).

27 Kluin, O. S., van der Mei, H. C., Busscher, H. J. \& Neut, D. A surface-eroding antibiotic delivery system based on poly-(trimethylene carbonate). Biomaterials 30, 4738-4742 (2009).

28 Dave, R. N., Joshi, H. M. \& Venugopalan, V. P. Novel biocatalytic polymer based antimicrobial coatings as potential ureteral biomaterial: preparation and in vitro performance evaluation. Antimicrob Agents Chemother 55, 845-853 (2011).

29 Barrow, W. W. Microsphere technology for chemotherapy of mycobacterial infections. Curr. Pharm. Des. 10, 3275-3284 (2004).

30 Siepmann, F., Siepmann, J., Walther, M., MacRae, R. J. \& Bodmeier, R. Polymer blends for controlled release coatings. J. Control. Release 125, 1-15 (2008).

$31 \mathrm{Li}, \mathrm{H}$. \& Chang, J. Preparation, characterization and in vitro release of gentamicin from PHBV/wollastonite composite microspheres. J. Control. Release 107, 463-473 (2005).

32 Xue, W., Liu, X., Zheng, X. \& Ding, C. In vivo evaluation of plasma-sprayed wollastonite coating. Biomaterials 26, 3455-3460 (2005).

33 Schnieders, J., Gbureck, U., Thull, R. \& Kissel, T. Controlled release of gentamicin from calcium phosphate-poly(lactic acid-co-glycolic acid) composite bone cement. Biomaterials 27, 4239-4249 (2006).

$34 \mathrm{Liu}, \mathrm{H}$. et al. Hydroxyapatite/polyurethane scaffold incorporated with drug-loaded ethyl cellulose microspheres for bone regeneration. J. Biomed. Mater. Res. B Appl. Biomater. 95, 36-46 (2010).

35 Adams, S. B. Jr, Shamji, M. F., Nettles, D. L., Hwang, P. \& Setton, L. A. Sustained release of antibiotics from injectable and thermally responsive polypeptide depots. J. Biomed. Mater. Res. B Appl. Biomater. 90, 67-74 (2009).

36 Elsner, J. J., Berdicevsky, I. \& Zilberman, M. In vitro microbial inhibition and cellular response to novel biodegradable composite wound dressings with controlled release of antibiotics. Acta. Biomater. 7, 325-336 (2011).

37 Carlo Ceschel, G. et al. Design and evaluation in vitro of controlled release mucoadhesive tablets containing chlorhexidine. Drug Dev. Ind. Pharm. 32, 53-61 (2006).

38 Keegan, G. et al. An in vitro assessment of bioadhesive zinc/carbomer complexes for antimicrobial therapy within the oral cavity. Int. J. Pharm. 340, 92-96 (2007).

39 Gates, K. A., Grad, H., Birek, P. \& Lee, P. I. A new bioerodible polymer insert for the controlled release of metronidazole. Pharm. Res. 11, 1605-1609 (1994).

40 Chowdary, K. P. \& Rao, Y. S. Mucoadhesive microspheres for controlled drug delivery. Biol. Pharm. Bull. 27, 1717-1724 (2004).

41 Govender, S. et al. Optimisation and characterisation of bioadhesive controlled release tetracycline microspheres. Int. J. Pharm. 306, 24-40 (2005).

42 Majithiya, R. J. \& Murthy, R. S. Chitosan-based mucoadhesive microspheres of clarithromycin as a delivery system for antibiotic to stomach. Curr. Drug Deliv. 2, 235-242 (2005).

43 Gopinath, D., Kumar, M. S., Selvaraj, D. \& Jayakumar, R. Pexiganan-incorporated collagen matrices for infected wound-healing processes in rat. J. Biomed. Mater. Res. A 73, 320-331 (2005)

44 Sripriya, R., Kumar, M. S., Ahmed, M. R. \& Sehgal, P. K. Collagen bilayer dressing with ciprofloxacin, an effective system for infected wound healing. J. Biomater. Sci. Polym. Ed. 18, 335-351 (2007).

45 Karlgard, C. C., Jones, L. W. \& Moresoli, C. Ciprofloxacin interaction with silicon-based and conventional hydrogel contact lenses. Eye Contact Lens 29, 83-89 (2003).

46 Venkatesh, S., Sizemore, S. P. \& Byrne, M. E. Biomimetic hydrogels for enhanced loading and extended release of ocular therapeutics. Biomaterials 28, 717-724 (2007).

$47 \mathrm{Ali}, \mathrm{M}$. et al. Zero-order therapeutic release from imprinted hydrogel contact lenses within in vitro physiological ocular tear flow. J. Control. Release 124, 154-162 (2007).

48 Ciolino, J. B. et al. A drug-eluting contact lens. Invest. Ophthalmol. Vis. Sci. 50, 3346-3352 (2009).

49 Radin, S., El-Bassyouni, G., Vresilovic, E. J., Schepers, E. \& Ducheyne, P. In vivo tissue response to resorbable silica xerogels as controlled-release materials. Biomaterials 26 1043-1052 (2005).

50 Radin, S. \& Ducheyne, P. Controlled release of vancomycin from thin sol-gel films on titanium alloy fracture plate material. Biomaterials 28, 1721-1729 (2007).

51 Adams, C. S. et al. Controlled release of vancomycin from thin sol-gel films on implant surfaces successfully controls osteomyelitis. J. Orthop. Res. 27, 701-709 (2009).

52 Chuang, H. F., Smith, R. C. \& Hammond, P. T. Polyelectrolyte multilayers for tunable release of antibiotics. Biomacromolecules 9, 1660-1668 (2008).

53 Moskowitz, J. S. et al. The effectiveness of the controlled release of gentamicin from polyelectrolyte multilayers in the treatment of Staphylococcus aureus infection in a rabbit bone model. Biomaterials 31, 6019-6030 (2010).

54 Wong, S. Y. et al. Dual functional polyelectrolyte multilayer coatings for implants: permanent microbicidal base with controlled release of therapeutic agents. J. Am. Chem. Soc. 132, 17840-17848 (2010).

55 Bilensoy, E. \& Hincal, A. A. Recent advances and future directions in amphiphilic cyclodextrin nanoparticles. Expert Opin. Drug Deliv. 6, 1161-1173 (2009).

56 Blanchemain, N. et al. Polyester vascular prostheses coated with a cyclodextrin polymer and activated with antibiotics: cytotoxicity and microbiological evaluation. Acta. Biomater. 4, 1725-1733 (2008). 
57 Aleem, O., Kuchekar, B., Pore, Y. \& Late, S. Effect of beta-cyclodextrin and hydroxypropyl beta-cyclodextrin complexation on physicochemical properties and antimicrobial activity of cefdinir. J. Pharm. Biomed. Anal. 47, 535-540 (2008).

58 Jianbin, C., Liang, C., Hao, X. \& Dongpin, M. Preparation and study on the solid inclusion complex of ciprofloxacin with beta-cyclodextrin. Spectrochim. Acta. A Mol. Biomol. Spectrosc. 58, 2809-2815 (2002).

59 Young, R. M. et al. The results of in situ prosthetic replacement for infected aortic grafts. Am. J. Surg. 178, 136-140 (1999).

60 Blanchemain, N. et al. Vascular prostheses with controlled release of antibiotics Part 1: surface modification with cyclodextrins of PET prostheses. Biomol. Eng. 24, 149-153 (2007).

61 Blanchemain, N. et al. Methyl-beta-cyclodextrin modified vascular prosthesis: influence of the modification level on the drug delivery properties in different media. Acta. Biomater. 7, 304-314 (2011).

62 Domingues, Z. R. et al. Bioactive glass as a drug delivery system of tetracycline and tetracycline associated with beta-cyclodextrin. Biomaterials 25, 327-333 (2004).

$63 \mathrm{Xu}$, J., Li, X. \& Sun, F. Cyclodextrin-containing hydrogels for contact lenses as a platform for drug incorporation and release. Acta. Biomater. 6, 486-493 (2010).

64 Hoste, K., De Winne, K. \& Schacht, E. Polymeric prodrugs. Int. J. Pharm. 277, 119-131 (2004).

65 Jung, Y. \& Kim, Y. M. Evaluation of cellulose xanthate-metal-tetracycline complexes as a polymeric antibacterial agent with prolonged antibacterial activity. Drug Deliv. 15, 31-35 (2008).

66 Imbuluzqueta, E. et al. Novel bioactive hydrophobic gentamicin carriers for the treatment of intracellular bacterial infections. Acta. Biomater. (2010).

67 Zhang, L., Pornpattananangku, D., Hu, C. M. \& Huang, C. M. Development of nanoparticles for antimicrobial drug delivery. Curr. Med. Chem. 17, 585-594 (2010).

68 Zhang, L. et al. Nanoparticles in medicine: therapeutic applications and developments. Clin. Pharmacol. Ther. 83, 761-769 (2008).

69 Liu, P. F., Lo, C. W., Chen, C. H., Hsieh, M. F. \& Huang, C. M. Use of nanoparticles as therapy for methicillin-resistant Staphylococcus aureus infections. Curr. Drug Metab. 10, 875-884 (2009).

$70 \mathrm{Kim}, \mathrm{K}$. et al. Physicochemical characterizations of self-assembled nanoparticles of glycol chitosan-deoxycholic acid conjugates. Biomacromolecules 6, 1154-1158 (2005).

71 Liu, C. G., Desai, K. G., Chen, X. G. \& Park, H. J. Linolenic acid-modified chitosan for formation of self-assembled nanoparticles. J. Agric. Food Chem. 53, 437-441 (2005).

72 Hyung Park, J. et al. Self-assembled nanoparticles based on glycol chitosan bearing hydrophobic moieties as carriers for doxorubicin: in vivo biodistribution and anti-tumor activity. Biomaterials 27, 119-126 (2006).

73 Zhang, J., Chen, X. G., Li, Y. Y. \& Liu, C. S. Self-assembled nanoparticles based on hydrophobically modified chitosan as carriers for doxorubicin. Nanomedicine $\mathbf{3}$, 258-265 (2007).
74 Peng, K. T. et al. Treatment of osteomyelitis with teicoplanin-encapsulated biodegradable thermosensitive hydrogel nanoparticles. Biomaterials 31, 5227-5236 (2010).

75 Rojanasakul, Y. et al. The transport barrier of epithelia: a comparative study on membrane permeability and charge selectivity in the rabbit. Pharm. Res. 9, 1029-1034 (1992).

76 Dillen, K., Vandervoort, J., Van den Mooter, G. \& Ludwig, A. Evaluation of ciprofloxacinloaded Eudragit RS100 or RL100/PLGA nanoparticles. Int. J. Pharm. 314, 72-82 (2006).

77 Das, S., Suresh, P. K. \& Desmukh, R. Design of Eudragit RL 100 nanoparticles by nanoprecipitation method for ocular drug delivery. Nanomedicine 6, 318-323 (2010).

78 Gupta, H., Aqil, M., Khar, R. K., Ali, A., Bhatnagar, A. \& Mittal, G. Sparfloxacin-loaded PLGA nanoparticles for sustained ocular drug delivery. Nanomedicine 6, 324-333 (2010).

79 Gupta, H. et al. Biodegradable levofloxacin nanoparticles for sustained ocular drug delivery. J. Drug Target. (2010).

80 Sung, J. C. et al. Formulation and pharmacokinetics of self-assembled rifampicin nanoparticle systems for pulmonary delivery. Pharm. Res. 26, 1847-1855 (2009).

$81 \mathrm{Liu}, \mathrm{L}$. et al. Polymeric micelles anchored with TAT for delivery of antibiotics across the blood-brain barrier. Biopolymers 90, 617-623 (2008).

82 Sharma, A., Sharma, S. \& Khuller, G. K. Lectin-functionalized poly (lactide-coglycolide) nanoparticles as oral/aerosolized antitubercular drug carriers for treatment of tuberculosis. J. Antimicrob. Chemother. 54, 761-766 (2004).

83 Cheow, W. S., Chang, M. W. \& Hadinoto, K. Antibacterial efficacy of inhalable levofloxacin-loaded polymeric nanoparticles against E. coli biofilm cells: the effect of antibiotic release profile. Pharm. Res. 27, 1597-1609 (2010).

84 Lecaroz, C., Gamazo, C. \& Blanco-Prieto, M. J. Nanocarriers with gentamicin to treat intracellular pathogens. J. Nanosci. Nanotechnol. 6, 3296-3302 (2006).

85 Ferraz, M. P., Mateus, A. Y., Sousa, J. C. \& Monteiro, F. J. Nanohydroxyapatite microspheres as delivery system for antibiotics: release kinetics, antimicrobial activity, and interaction with osteoblasts. J. Biomed. Mater. Res. A 81, 994-1004 (2007).

86 Huang, D. et al. Antibacterial chitosan coating on nano-hydroxyapatite/polyamide66 porous bone scaffold for drug delivery. J. Biomater. Sci. Polym. Ed. 22, 931-944 (2010).

87 Zou, Q., Li, Y., Zhang, L., Zuo, Y. \& Li, J. Antibiotic delivery system using nanohydroxyapatite/chitosan bone cement consisting of berberine. J. Biomed. Mater. Res. A 89, 1108-1117 (2009).

88 Hesaraki, S., Moztarzadeh, F., Nemati, R. \& Nezafati, N. Preparation and characterization of calcium sulfate-biomimetic apatite nanocomposites for controlled release of antibiotics. J. Biomed. Mater. Res. B Appl. Biomater. 91, 651-661 (2009).

89 El-Ghannam, A., Ahmed, K. \& Omran, M. Nanoporous delivery system to treat osteomyelitis and regenerate bone: gentamicin release kinetics and bactericidal effect. J. Biomed. Mater. Res. B Appl. Biomater. 73, 277-284 (2005). 